\title{
COMUNICAÇÃO
}

\section{CONTROLE DO AMADURECIMENTO DE BANANA 'PRATA-ANÃ' ARMAZENADA SOB REFRIGERAÇÃO E ATMOSFERA MODIFICADA PASSIVA COM O USO DO 1-METILCICLOPROPENO}

\author{
Control of the ripening of banana 'Prata Anã' stored under refrigeration and passive modified \\ atmosphere with use of 1-methylcyclopropene
}

\author{
Luciana Costa Lima ${ }^{1}$, Sérgio Marques Costa ${ }^{2}$, Mário Sérgio Carvalho Dias ${ }^{3}$, \\ Ramilo Nogueira Martins ${ }^{4}$, Pedro Martins Ribeiro Júnior ${ }^{5}$
}

\begin{abstract}
RESUMO
O 1- Metilciclopropeno (1-MCP) é um produto inovador que inibe a ação do etileno em vegetais, retardando o início do amadurecimento de pomáceas, frutas de caroço e frutas tropicais. Com este trabalho objetivou-se avaliar a eficiência de diferentes concentrações do 1-MCP no controle do amadurecimento de bananas 'Prata-Anã' produzidas no Norte de Minas Gerais, armazenadas a $12^{\circ} \mathrm{C}$ e $95 \%$ de UR sob atmosfera modificada passiva. Os cachos foram colhidos no grau 1 de coloração da casca, que corresponde ao estádio verde de maturação. Foram utilizadas somente as segundas pencas dos cachos selecionados e estas foram separadas em buquês de 4 frutos. Cada parcela constou de 4 repetições e cada repetição 1 buquê. As concentrações do 1-MCP aplicadas foram: 0, 30, 60 e $90 \mathrm{ppb}$. Os frutos foram acondicionados em bandejas de isopor e embalados em filme de PVC de 15 micras, armazenados a $12^{\circ} \mathrm{C}$ e $95 \%$ de UR, sendo avaliados aos 10, 15, 20, e 25 dias. As avaliações realizadas constaram de diâmetro, grau de coloração da casca, firmeza, sólidos solúveis, acidez titulável e pH. A aplicação do 1-MCP foi eficaz em retardar o amadurecimento de bananas 'Prata-Anã' cultivadas na região Norte de Minas Gerais. As concentrações de 30, 60 e 90 ppb não apresentaram efeito diferenciado quanto às características avaliadas, podendo ser utilizada a concentração de 30 ppb, com economia do produto, obtendo-se os mesmos benefícios das concentrações de 60 e 90 ppb.
\end{abstract}

Termos para indexação: 1-MCP, conservação pós-colheita, Musa spp.

\begin{abstract}
Methylcyclopropene (1-MCP) is an innovating chemical which inhibits the action of ethylene in plants, delaying the onset of the ripening of pomaceous fruits, stone fruits and tropical fruits. The present work intended to evaluate the efficiency of different concentrations of 1-MCP upon the control of ripening of bananas 'Prata Anã' produced in Northern Minas Gerais State (Brazil), stored at $12^{\circ} \mathrm{C}$ and $95 \%$ of $\mathrm{RH}$ under passive modified atmosphere. The clusters were harvested at degree 1 of skin coloration, which corresponds to the unripe stage of maturation. Only the second bunches of cluster were selected which were separated into bouquet of four fruit were harvested. Each plot consisted of four replicates and each replicate of one bouquet. The concentrations of 1-MCP applied were: 0, 30, 60 and $90 \mathrm{ppb}$. The fruit were packed into plastic foam trays and wrapped in 15-micron PVC film, stored at $12^{\circ} \mathrm{C}$ and $95 \%$ of $\mathrm{RH}$, being evaluated at 10,15, 20 and 25 days. The performed evaluations consisted of diameter, degree of skin coloration, firmness, soluble solids, titrable acidity and pH. Application of 1-MCP was effective in delaying the ripening of bananas 'Prata Anã' grown in the North region of Minas Gerais State. The concentrations of 30, 60 and 90 ppb presented no distinct effect as regard to the evaluated characteristics, the concentration of 30ppb being able to be employed with a saving of the chemical, obtaining the same benefits as the concentrations of 60 and $90 \mathrm{ppb}$.
\end{abstract}

Index terms: 1-MCP, post-harvest conservation, Musa spp.

(Recebido para publicação em 30 de abril de 2004 e aprovado em 4 de março de 2005)

A banana, Musa spp. é uma das frutas mais consumidas no mundo, sendo cultivada na maioria dos países tropicais. O Brasil é o segundo produtor de bananas, com aproximadamente $11,2 \%$ da produção mundial.
Sua participação no mercado externo é muito reduzida, sendo $99,0 \%$ da produção destinada ao mercado interno, com um consumo per capita anual de $40 \mathrm{~kg}$ (FAO, 2004).

\footnotetext{
1. Engenheira Agrônoma. M.Sc. Aluna de Doutorado em Horticultura da Universidade Estadual Paulista Júlio de Mesquita Filho - Botucatu, SP limalc@fca.unesp.br

2. Engenheiro Agrônomo - marxcosta@hotmail.com

3. Engenheiro Agrônomo D.Sc. Pesquisador do Centro Tecnológico do Norte de Minas -EPAMIG - Caixa Postal 12 - $39.440-000$ - Nova Porteirinha, MG diasmsc@nortecnet.com.br

4. Engenheiro Agrônomo Aluno de Mestrado em Ciência dos Alimentos na Universidade Federal de Lavras/UFLA - Caixa Postal 3037 - $37.200-000$ Lavras, MG - martinsnr@hotmail.com

5. Engenheiro Agrônomo Aluno de Mestrado em Fitopatologia da Universidade Federal de Lavras/UFLA - pedromartinsjr@bol.com.br
} 
O Estado de Minas Gerais ocupa a quinta posição na produção nacional de bananas. Na região Norte de Minas Gerais, a bananicultura representa 25,98\% da área cultivada com banana no estado, diferenciando-se das demais por ser irrigada e trabalhar basicamente com a cultivar Prata-anã (SOUTO et al., 1998).

O amadurecimento caracteriza-se por uma série de transformações no fruto, marcadamente mudanças na coloração da casca e na firmeza, além da intensificação do sabor e aroma. Segundo Rocha (1984), durante o amadurecimento ocorre a conversão do amido em glicose, frutose e sacarose. Observam-se também, mudanças na acidez, sólidos solúveis e a transformação da protopectina ou pectina insolúvel em pectinas solúveis, resultando em modificações na firmeza do fruto.

O etileno é considerado o hormônio natural do amadurecimento e o aumento na sua biossíntese até concentrações que estimulam o processo, é o evento que marca a transição entre as fases de crescimento e senescência do fruto (CHITARRA \& CHITARRA, 1990).

A refrigeração é um dos meios mais eficazes de reduzir os processos metabólicos em frutos e, geralmente, é utilizada associada às técnicas tais como atmosfera controlada (SEYMOUR et al., 1987), atmosfera modificada por embalagens plásticas (TAN et al., 1990), absorvedores de etileno (SATYAN et al., 1992) e atualmente à aplicação do 1-Metilciclopropeno.

O 1- Metilciclopropeno (1-MCP) é um produto inovador, que inibe a ação do etileno em plantas e frutos armazenados. Ele age pela fixação preferencial ao receptor de etileno, inibindo, deste modo, os efeitos do hormônio procedente de fontes internas e externas. O produto tem demonstrado excelente atividade no retardamento do início do amadurecimento de pomáceas, frutas de caroço e frutas tropicais. Resultados positivos em testes têm sido obtidos com bananas, tomates, pepinos, pimentões, brócolis, diversas hortaliças folhosas, flores de corte e de vaso (ROHM AND HAAS COMPANY, 2000).

Em frutas tropicais, tal como banana, o 1-MCP provou exercer um impressionante efeito sobre o amadurecimento destas frutas. Os estudos demostram que, em bananas do sub-grupo Cavendish, concentrações tão baixas quanto $100 \mathrm{ppb}$ do produto, quase dobram o seu período de conservação. O 1-MCP, em combinação com a atmosfera modificada (AM) que propicia níveis baixos de $\mathrm{O}_{2}$ dentro da embalagem, mantém a cor verde das bananas durante 6 semanas (ROHM AND HAAS COMPANY, 2000).

Com este trabalho, objetivou-se prolongar a vida pós-colheita de bananas 'Prata-Anã', produzidas na região
Norte de Minas Gerais, mediante aplicação de diferentes concentrações do 1 - Metilciclopropeno em atmosfera modificada passiva sob refrigeração a $12^{\circ} \mathrm{C}$ e $95 \%$ de UR, visando a exportação desta fruta com alta qualidade.

Foi conduzido um experimento no Laboratório de Pós-colheita de Frutos do Centro Tecnológico do Norte de Minas Gerais, localizado na cidade de Nova Porteirinha - MG, pertencente à Empresa de Pesquisa Agropecuária de Minas Gerais (EPAMIG). Utilizaram-se buquês de 4 frutos, retirados das segundas pencas de cachos colhidos e selecionados de bananas 'Prata-Anã'. Os buquês foram tratados por 16 horas com as concentrações de 0, 30, 60 e 90ppb do 1 - Metilciclopropeno (1 - MCP), na concentração de $0,14 \%$ de ingrediente ativo a $12^{\circ} \mathrm{C}$, em caixas plásticas hermeticamente fechadas. Logo após, os mesmos foram acondicionados em bandejas de isopor e embalados em filme de PVC de 15 micras de espessura e armazenados a $12^{\circ} \mathrm{C}$ e $95 \%$ de UR. Os frutos permaneceram armazenados por 25 dias, sendo analisados quanto as características físicas e químicas a cada 5 dias a partir do $10^{\circ}$ dia de armazenamento.

O delineamento experimental foi o inteiramente casualizado, com 4 repetições e as parcelas experimentais constaram de um buquê de 4 frutos.

\section{As análises realizadas foram:}

Diâmetro - Obtido pela medição em paquímetro expressando-se os resultados em mm.

Grau de coloração da casca - determinada pela comparação com tabela de cores: 1 - Totalmente verde; 2 - Verde com traços amarelos; 3 - Mais verde que amarelo; 4 - Mais amarelo que verde; 5 - Amarelo com pontas verdes; 6 - Totalmente amarelo; 7 - Amarelo com leves manchas marrons (WILLS et al., 1982).

Firmeza da polpa - utilizou-se um penetrômetro (marca FERRARI) com ponteira de $8 \mathrm{~mm}$, realizando uma leitura na parte central do fruto descascado. Os resultados foram expressos em Newtons (N).

Sólidos Solúveis (SS) - o teor de SS foi obtido por refratometria, utilizando o refratômetro manual (marca ATAGO, modelo N-1E) com leitura na faixa de 0 a 32\%. A determinação segundo a através de metodologia descrita em Carvalho et al. (1990);

Acidez Titulável (AT) - a AT foi determinada por titulometria, sendo os resultados foram expressos em g de ácido málico. $100^{-1} \mathrm{~g}$ de polpa (CARVALHO et al., 1990).

pH - a determinação foi feita por um pHmetro digital (marca TECNAL), de acordo com a metodologia descrita em Carvalho et al. (1990); 
Os frutos, após a colheita, encontravam-se no grau 1 de coloração da casca (totalmente verdes) apresentando diâmetro médio de $36 \mathrm{~mm}$, firmeza da polpa de 31,58N, pH 5,7, sólidos solúveis 1,3\% e acidez titulável $0,19 \mathrm{~g}$ de ácido málico. $100^{-1} \mathrm{~g}$ de polpa.

Analisando-se os resultados para o grau de coloração da casca, percebe-se que a coloração modificou-se com o processo de amadurecimento dos frutos (Tabela 1).

Frutos não tratados com o 1-MCP (0 ppb), aos 10 dias de armazenamento, já apresentavam grau 5 de coloração da casca, ou seja, os frutos estavam amarelos, mas ainda apresentavam pontas verdes. Com o decorrer do armazenamento, essa coloração ainda sofreu modificações, apresentando ao final do experimento, grau de coloração da casca 7 (frutos amarelos com manchas marrons).

Com a aplicação do 1-MCP (30, 60 e 90 ppb), a coloração da casca manteve-se no grau 3 (mais verde do que amarelo) até os 15 dias de armazenamento, passando para o grau 4 (mais amarelo do que verde) dos 20 dias até o final do experimento. Isso demonstra que $o$ produto retardou a perda da cor verde da casca em frutos tratados, independente da concentração utilizada.

Jiang et al. (1999), citados por Botrel et al. (2002), trabalhando com bananas do grupo Cavendish, também verificaram que o 1-MCP é um potente retardador do amadurecimento, pois observaram retenção da cor verde da casca.

Com relação à firmeza da polpa, observa-se pela Tabela 2, que frutos tratados com o 1-MCP (30, 60 e 90 $\mathrm{ppb}$ ), apresentaram firmeza de polpa significativamente maior, quando comparados aos frutos não tratados (0 ppb) durante os 25 dias de armazenamento. Porém, os frutos sob as concentrações de 30, 60 e 90 ppb não diferiram entre si. Botrel et al. (2002), trabalhando com bananas 'Prata-Anã', também encontraram valores maiores de firmeza da polpa em frutos tratados com o 1-MCP (10, 30 e $90 \mathrm{ppb})$ e valores menores em frutos não tratados $(0 \mathrm{ppb})$, quando estes foram armazenados à temperatura ambiente.

Pelos resultados obtidos na Tabela 3, observa-se que não houve variação significativa na porcentagem de sólidos solúveis entre os frutos tratados com o 1-MCP, independente da concentração utilizada (30, 60 e 90 ppb), durante o período de 25 dias de armazenamento em $\mathrm{AM}$ a $12^{\circ} \mathrm{C}$ e $95 \%$ de UR. Este fato indica que, tais frutos encontravam-se em estádio de maturação semelhante ao final do período experimental. No entanto, frutos não tratados com o 1-MCP (0 ppb), apresentaram maior teor de sólidos quando comparados aos frutos tratados (30, 60 e $90 \mathrm{ppb}$ ) durante todo o período experimental, o que mostra um avanço do amadurecimento nestes frutos.

Valores elevados de sólidos solúveis também foram encontrados por Botrel et al. (2002) em frutos não tratados com o 1-MCP (0 ppb), porém, sem o uso da refrigeração e AM.

No que se refere a acidez titulável e $\mathrm{pH}$, a aplicação do 1-MCP (30, 60 e 90 ppb) retardou o incremento natural da acidez e a redução do $\mathrm{pH}$, observados durante o amadurecimento de bananas (Tabela 4). Nenhuma diferença foi notada, com relação à acidez e o pH, entre os frutos tratados com 1 - MCP.

Frutos não tratados (0 ppb), apresentaram valores de acidez que variaram de $0,53 \mathrm{~g}$ a $0,58 \mathrm{~g}$ de ácido málico. $100^{-1} \mathrm{~g}$ de polpa e frutos tratados $(30,60$ e 90 ppb) 0,21 a $0,37 \mathrm{~g}$ de ácido málico. $100^{-1} \mathrm{~g}$ de polpa. Tais valores confirmam um maior avanço no amadurecimento de frutos não tratados com o 1-MCP.

Analisando os resultados de $\mathrm{pH}$, nota-se que, de acordo com a Tabela 4, o pH de frutos tratados com 1-MCP, independente da concentração (30, 60 e 90 $\mathrm{ppb})$, foi superior que o dos frutos não tratados (0 ppb) durante o período experimental. Os valores de $\mathrm{pH}$ dos frutos tratados com o 1 - MCP variaram de 5,06 a 5,65 ao passo que o $\mathrm{pH}$ dos frutos controle oscilou de 4,54 a 4,63.

TABELA 1 - Graus de coloração da casca de bananas 'Prata-Anã', armazenadas sob atmosfera modificada passiva, a $12^{\circ} \mathrm{C}$ e $95 \%$ de UR durante 25 dias.

\begin{tabular}{ccccc}
\hline \multirow{2}{*}{ TRATAMENTOS } & \multicolumn{4}{c}{ ARMAZENAMENTO (DIAS) } \\
\cline { 2 - 5 } & $\mathbf{1 0}$ & $\mathbf{1 5}$ & $\mathbf{2 0}$ & $\mathbf{2 5}$ \\
\hline $0 \mathrm{ppb}$ & $5 \mathrm{a}$ & $6 \mathrm{a}$ & $7 \mathrm{a}$ & $7 \mathrm{a}$ \\
$30 \mathrm{ppb}$ & $3 \mathrm{~b}$ & $3 \mathrm{~b}$ & $4 \mathrm{~b}$ & $4 \mathrm{~b}$ \\
$60 \mathrm{ppb}$ & $3 \mathrm{~b}$ & $3 \mathrm{~b}$ & $4 \mathrm{~b}$ & $4 \mathrm{~b}$ \\
$90 \mathrm{ppb}$ & $3 \mathrm{~b}$ & $3 \mathrm{~b}$ & $4 \mathrm{~b}$ & $4 \mathrm{~b}$ \\
\hline
\end{tabular}

Médias seguidas de mesma letra, na coluna, não diferem entre si pelo teste de Tukey ao nível de 5\% de probabilidade.

Ciênc. agrotec., Lavras, v. 29, n. 2, p. 476-480, mar./abr., 2004 
TABELA 2 - Valores médios de firmeza da polpa (N) de bananas 'Prata-Anã', armazenadas sob atmosfera modificada passiva, a $12^{\circ} \mathrm{C}$ e $95 \%$ de UR durante 25 dias.

\begin{tabular}{ccccc}
\hline \multirow{2}{*}{ TRATAMENTOS } & \multicolumn{4}{c}{ ARMAZENAMENTO (DIAS) } \\
\cline { 2 - 5 } & $\mathbf{1 0}$ & $\mathbf{1 5}$ & $\mathbf{2 0}$ & $\mathbf{2 5}$ \\
\hline $0 \mathrm{ppb}$ & $16,10 \mathrm{~b}$ & $6,98 \mathrm{~b}$ & $6,09 \mathrm{~b}$ & $6,58 \mathrm{~b}$ \\
$30 \mathrm{ppb}$ & $34,56 \mathrm{a}$ & $30,11 \mathrm{a}$ & $33,72 \mathrm{a}$ & $32,87 \mathrm{a}$ \\
$60 \mathrm{ppb}$ & $33,32 \mathrm{a}$ & $32,56 \mathrm{a}$ & $32,78 \mathrm{a}$ & $25,62 \mathrm{a}$ \\
$90 \mathrm{ppb}$ & $33,05 \mathrm{a}$ & $33,36 \mathrm{a}$ & $32,47 \mathrm{a}$ & $31,45 \mathrm{a}$ \\
\hline
\end{tabular}

Médias seguidas de mesma letra, na coluna, não diferem entre si pelo teste de Tukey ao nível de 5\% de probabilidade.

TABELA 3 - Valores médios de sólidos solúveis (\%) de bananas 'Prata-Anã', armazenadas sob atmosfera modificada passiva, a $12^{\circ} \mathrm{C}$ e $95 \%$ de UR durante 25 dias.

\begin{tabular}{ccccc}
\hline \multirow{2}{*}{ TRATAMENTOS } & \multicolumn{4}{c}{ ARMAZENAMENTO (DIAS) } \\
\cline { 2 - 5 } & $\mathbf{1 0}$ & $\mathbf{1 5}$ & $\mathbf{2 0}$ & $\mathbf{2 5}$ \\
\hline $0 \mathrm{ppb}$ & $5,2 \mathrm{a}$ & $7,5 \mathrm{a}$ & $8,8 \mathrm{a}$ & $8,8 \mathrm{a}$ \\
$30 \mathrm{ppb}$ & $2,6 \mathrm{~b}$ & $3,0 \mathrm{~b}$ & $4,7 \mathrm{~b}$ & $3,5 \mathrm{~b}$ \\
$60 \mathrm{ppb}$ & $1,8 \mathrm{~b}$ & $2,1 \mathrm{~b}$ & $2,9 \mathrm{~b}$ & $4,0 \mathrm{~b}$ \\
$90 \mathrm{ppb}$ & $1,8 \mathrm{~b}$ & $2,2 \mathrm{~b}$ & $2,7 \mathrm{~b}$ & $4,0 \mathrm{~b}$ \\
\hline
\end{tabular}

Médias seguidas de mesma letra, na coluna, não diferem entre si pelo teste de Tukey ao nível de 5\% de probabilidade.

TABELA 4 - Valores médios de acidez titulável (g de ácido málico.100-1 g de polpa) e pH de bananas 'Prata-Anã', armazenadas sob atmosfera modificada passiva, a $12^{\circ} \mathrm{C}$ e $95 \%$ de UR durante 25 dias.

\begin{tabular}{ccccc}
\hline & \multicolumn{4}{c}{ ARMAZENAMENTO (DIAS) } \\
\cline { 2 - 5 } TRATAMENTOS & $\mathbf{1 0}$ & $\mathbf{1 5}$ & $\mathbf{2 0}$ & $\mathbf{2 5}$ \\
\cline { 2 - 5 } & $0,53 \mathrm{a}$ & $0,64 \mathrm{a}$ & $0,60 \mathrm{a}$ & $0,58 \mathrm{a}$ \\
& $0,25 \mathrm{~b}$ & $0,32 \mathrm{~b}$ & $0,28 \mathrm{~b}$ & $0,33 \mathrm{~b}$ \\
$30 \mathrm{ppb}$ & $0,29 \mathrm{~b}$ & $0,30 \mathrm{~b}$ & $0,30 \mathrm{~b}$ & $0,37 \mathrm{~b}$ \\
$60 \mathrm{ppb}$ & $0,27 \mathrm{~b}$ & $0,27 \mathrm{~b}$ & $0,21 \mathrm{~b}$ & $0,37 \mathrm{~b}$ \\
\hline $0 \mathrm{ppb}$ & & & $\mathbf{p H}$ & \\
\hline & $4,62 \mathrm{~b}$ & $4,54 \mathrm{~b}$ & $4,56 \mathrm{~b}$ & $4,63 \mathrm{~b}$ \\
\hline $0 \mathrm{ppb}$ & $5,65 \mathrm{a}$ & $5,27 \mathrm{a}$ & $5,51 \mathrm{a}$ & $5,20 \mathrm{a}$ \\
$60 \mathrm{ppb}$ & $5,50 \mathrm{a}$ & $5,41 \mathrm{a}$ & $5,40 \mathrm{a}$ & $5,06 \mathrm{a}$ \\
$90 \mathrm{ppb}$ & $5,54 \mathrm{a}$ & $5,38 \mathrm{a}$ & $5,36 \mathrm{a}$ & $5,23 \mathrm{a}$ \\
\hline
\end{tabular}

Médias seguidas de mesma letra, na coluna, não diferem entre si pelo teste de Tukey ao nível de 5\% de probabilidade. 
Conclui-se que a aplicação do 1-MCP é eficaz em retardar o início do amadurecimento em bananas 'Prata- Anã' cultivadas na região Norte de Minas Gerais. Porém, as concentrações de 30, 60 e 90 ppb não apresentam efeito diferenciado quanto às características avaliadas em bananas 'Prata-Anã', quando embaladas e refrigeradas a $12^{\circ} \mathrm{C}$ e $95 \%$ de UR por um período de 25 dias. Deste modo, deve ser utilizada a concentração de $30 \mathrm{ppb}$ para economia do produto, pois os benefícios são os mesmos quando comparados às concentrações de 60 e $90 \mathrm{ppb}$.

\section{AGRADECIMENTOS}

À empresa ROHM and HAAS, pelo auxílio financeiro e fornecimento do 1-MCP para o desenvolvimento deste trabalho.

\section{REFERÊNCIAS BIBLIOGRÁFICAS}

BOTREL, N.; FREIRE JÚNIOR, M.; VASCONCELOS, R. M. de; BARBOSA, H. T. G. Inibição do amadurecimento de banana 'Prata anã' com a aplicação do 1-Metilciclopropeno. Revista Brasileira de Fruticultura, Jaboticabal, São Paulo, v. 24, n. 1, p. 53-56, 2002.

CARVALHO, C. R. L.; MANTOVANI, D. M. B.; CARVALHO, P. R. N.; MORAES, P. M. Análises químicas de alimentos. Campinas: ITAL, 1990. 121 p.

CHITARRA, M. I. F.; CHITARRA, A. B. Pós-colheita de frutos e hortaliças: fisiologia e manuseio. Lavras: ESAL/FAEPE, 1990. 293 p.

FOOD AND AGRICULTURE ORGANIZATION. Disponível em: <http://apps.fao.org>. Acesso em: 8 out. 2004.
ROCHA, J. L. V. Fisiologia pós-colheita de banana. In: SIMPÓSIO BRASILEIRO SOBRE BANANICULTURA, 1., 1984, Jaboticabal. Anais... Jaboticabal: FCAVJ, 1984. p. 353-367.

ROHM AND HAAS COMPANY. 1Metilciclopropeno (1-MCP): agroFresh Inc. [S.l.], 2000. (Boletim técnico).

SATYAN, S.; SCOTT, K. J.; GRAHAM, D. Storage of banana bunches in sealed polyethylene tubes. The Journal of Horticultural Science, London, v. 67, p. 283-287, 1992.

SEYMOUR, G. B.; JOHN, P.; THOMPSON, A. K. Inhibition of degreening in the peel of bananas ripening at tropical temperatures: II. role of ethylene, oxygen and carbon dioxide. Annals of Applied Biology, Warwick, v. 110 , p. $153-161,1987$.

SOUTO, R. F.; RODRIGUES, M. G.; MENEGUCCI, J. L. P. Situação da bananicultura no Norte de Minas Gerais. In: SIMPÓSIO BRASILEIRO SOBRE BANANICULTURA, 4., 1998, Campo Grande. Anais... Campo Grande: [s.n.], 1998. p. 29-53.

TAN, S. C.; ALI, A. M.; SOON, C. T. The effect on $\mathrm{CO}_{2}$ on phenolic compounds during the storage of 'Mas' banana in polybag. Acta Horticulturae, The Hague, n. 269, p. 389, 1990.

WILLS, R. B. H.; PITAKSERIKUL, S.; SCOTT, K. J. Effects of pre-storage in low oxygen or high carbon dioxide concentrations on delaying the ripening of bananas. Australian Journal Agriculture Research, Victoria, v. 33, p. 1029-1036, 1982. 